\title{
Carlos Monsiváis y el campo académico de la comunicación: Interacción y sentidos
}

\author{
Tanius Karam Cárdenas* \\ Universidad Autónoma de la Ciudad de México
}

El objetivo de estas líneas es mostrar, a la manera de dos miradas cruzadas, cómo puede ser percibido Monsiváis por el campo de la comunicación, y qué dice el autor de Días de Guardar del propio campo. Para tal efecto se realiza una primera caracterización del campo académico de la comunicación (CAC), se propone una nueva interpretación desde lo que llamamos socio-semiótica. Posteriormente presentamos rápidamente los rasgos de la vida-obra monsivaita, para indagar sobre los dispositivos que el CAC usa para producir-reproducir una relación sígnica de Monsiváis en tanto referencia dominante. Finalmente hacemos un comentario sobre lo que Monsiváis ha dicho del CAC y de los comunicadores.

Palabras Claves: Semiótica, Práctica Cultural, Discurso, Campo académico de la Comunicación.

The objective of this abstract is to show, in a way of two crossed looks, how Monsivaiis can be perceived by the communication's field, and what does the author of Dias de Guardar says about the same field. For this purpose, a first characterization of the academic field of the communication (CAC) is done, with the intent of making a new interpretation from what we call socio-semiotica. Later on, we present the features of the life-work monsiv-

* Doctor en Ciencias de la Información por la Universidad Complutense de Madrid. Es profesor e investigador en la Academia de Comunicación de la Universidad Autónoma de la Ciudad de México desde 2002. En 2007 fue nombrado Coordinador del Colegio de Humanidades y Ciencias Sociales de la misma Universidad. Correo electrónico: tanius.karam@uacm.edu.mx 
aita, to investigate on devices that the CAC uses to produce-reproduce a signs relationship of Monsivaiis as a dominant reference. Finally we make a comment on what Monsivais has said of the CAC and the proffesionals in communication.

Key words: Semiótica, Cultural Practice, Speech, Academic Field of the Communication.

\section{INTRODUCCIÓN}

La figura de Carlos Monsiváis es una de las más emblemáticas. Salazar (2002) ha sugerido un movimiento que va de la heterodoxia a una suerte de fortalecimiento en un Monsiváis central, en el que hoy ha devenido como icono y símbolo. En este ensayo — que van a manejar de homenaje, por los 70 años del autor- queremos, aparte de recordar algunas características y atributos del autor, presentar algunas posibilidades metodológicas que nos permitan un conocimiento más complejo, como ciertas figuras son percibidas en comunidades especificas de interpretantes.

Monsiváis (como de hecho cualquier autor o referencia estudiada semiótica como "signo") es un pretexto para reflexionar sobre ciertas dinámicas al interior del campo académico, sobre la manera en que se producen significados o se relacionan representaciones. Proponemos algunos aspectos, de cómo ciertas comunidades científicas, seleccionan algunos signos los cuales se resaltan a través de ciertos dispositivos semióticos; al hacerlo, establecen algo más que una simple relación, conforman un esquema de percepción. Para ello, después de una propuesta para reflexionar sobre el campo académico, y conocer aspectos del autor, proponemos desde el análisis de algunos dispositivos socio-semióticos indagar por la circulación de Monsiváis en tanto una cadena sígnica que produce efectos de sentido en una comunidad, la cual al interactuar con él, se define a sí misma, en juegos cruzados.

I. EL CAMPO ACADÉMICO DE LA COMUNICACIÓN.

UNA INTERPRETACIÓN SOCIO-SEMIÓTICA

\subsection{Recuento de lo sabido}

Se acepta cada vez más en las comunidades de docentes, investigadores y editores la existencia de la figura llamada campo académico de la comunicación (CAC).

I42 - Tanius Karam Cárdenas 
La literatura sobre el tema es creciente, entre otras razones por el crecimiento exponencial escuelas y estudiantes de las diversas modalidades que agrupan el título de comunicación, al mismo tiempo se ha dado una evolución en las distintas perspectivas teóricas para estudiarlo que van desde un nivel historiográfico muy básico, la visión fenomenológica que ha aplicado Benassini a partir de Berger y Luckmann, o las interpretaciones desde perspectivas simbólicas como la de Sánchez Ruiz (2003).

Es a principios de los noventa que Fuentes Navarro comienza a hablar del campo, como un elemento que permitía objetivar las operaciones que realizan los agentes de conocimiento de la comunicación, y tener marcos generales para la búsqueda de la autonomía y legitimación. Fuentes Navarro (1994, pp. 70-71) aplica la idea de campo como herramienta para reconocer las tensiones y desfases entre los actores que se constituyen con sus prácticas, más que los ingredientes $\mathrm{y}$ articulaciones relativamente estables y homogéneas o las autorregulaciones con que un sistema preserva su identidad, esto es, su estructura. Por campo, Fuentes Navarro (siempre siguiendo a Bourdieu ${ }^{1}$ ) entiende algo más que el conjunto de instituciones en que se estudia la comunicación académica a nivel superior a: la teoría, la investigación, la formación universitaria y la profesión, y centramos el concepto en las prácticas que realizan actores o agentes sociales concretos — sujetos individuales y colectivos - con el fin de impulsar proyectos sociales específicos: en este caso estructuras de conocimiento y pautas de intervención sobre la comunicación social en nuestro país. Cuando se especifica "campo académico", no es a las prácticas sociales de comunicación (masivas o no) a las que se hace referencia, ni a las instituciones que se han especializado en su ejercicio y en su control social, sino a aquellas que toman a éstas como su referente, es decir, las que son realizadas principalmente por académicos (universitarios), con el propósito general de conocer, explicar e intervenir en la transformación intencionada de las prácticas sociales de comunicación.

Fuentes Navarro ha devenido en una especie de cronista del CAC que lo ha estudiado desde los sesenta cuando emerge y tiene como rasgos que van en sus primeras dos décadas (sesenta y setenta), de la desarticulación, inconsistencia disciplinar, dependencia estructural, crisis universitaria (inicios de la investigación académica, fuerte oposición entre empírico y críticos; hasta la legitimación académica en los noventa, donde observamos una autonomía relativa.

${ }^{1}$ La secuencia de obras del autor, ya conocida es La distinción (1979), El sentido práctico (1980), Cuestiones de sociología (1980).

Carlos Monsiváis y el campo académico de la comunicación: • 143 Interacción y sentidos 
Sobre las características de ese campo ha habido también distintos señalamientos. Por ejemplo, a finales del año Castillo y Tapia (1996) sintetizan algunos logros e inercias entre las que destacan la institucionalización y legitimación por el crecimiento que ofertan la licenciatura y la masiva demanda estudiantil; en contrasentido, no se ha legitimado por el avance epistemológico de la ciencia de la comunicación, ni la investigación que se realiza. A finales de la década pasada, dentro del Sistema Nacional de Investigadores (SNI) solamente 14 investigadores centraban sus estudios en comunicación; las plantas académicas se han caracterizado por tener predominante nivel de licenciatura y condiciones laborales no favorables, ya que la forma de contratación que predomina es el profesor de asignatura, cuya función básica es la docencia. Los perfiles profesionales de los académicos, son heterogéneos y no se han aprovechado la interdisciplinariedad; se conoce el número de alumnos inscritos y de egresados, pero no las funciones profesionales y sociales para las que fueron formados durante cuatro años de licenciatura.

En estos últimos años se ha dado una serie de fenómenos, que nos hablan de cambios y transformaciones como son la consolidación de espacios de postgrado (que se verifica en el aumento de las tesis de maestría y doctorado así como el peso que van teniendo quienes obtienen postgrados en el extranjero); la creación de nuevas revistas (sobre todo electrónicas) donde es posible encontrar los más diversos espacios, líneas y referencias. Asistimos a una etapa de fortalecimiento de algunos grupos de trabajo, ${ }^{2}$ cuerpos académicos e instancias diversas de apoyo al trabajo que proliferan — desarticuladamente todavía— sobretodo en regiones (más que en las grandes ciudades del país: D.F. Guadalajara y Monterrey). Un indicador del crecimiento en la producción, se ve en el aumento creciente de solicitudes para publicar en el Anuario CONEICC o en los coloquios anuales que realiza AMIC donde el número aumenta, lo que lleva a discusiones, por ejemplo, de pensar en anuarios especializados y no generales. Menos perceptible, aparece una reflexión incipiente sobre nuevos modelos de enseñanza (sobre lo cual se ha hablado mucho, pero se ha analizado empíricamente poco), que si bien es un fenómeno marginal vale la pena mencionarlo como un signo de modificación. ${ }^{3}$

\footnotetext{
${ }^{2}$ Podemos incluir varios ejemplos, la red famecon que estudia el tema de familia y medios coordinado por el Mtro. Guadarrama, la red de Estudios en Teorías de Comunicación (REDECOM) coordinada por Jesús Galindo, el Centro de Investigación de Comunicación (CINCO) coordinador por José Carlos Lozano, entre algunos otros.

${ }^{3}$ Por ejemplo para lo que hemos considerado el "quinto modelo de enseñanza de la comunicación”, ver el trabajo interesante de Macías, N. y Cardona, D. (2007). Comunicometodología.
}

I44 - Tanius Karam Cárdenas 
Sin embargo, en el balance se tiene que reconocer que aún persisten las carencias en aspectos vinculadas a la sistematización, poca organización institucional a nivel regional y nacional; falta de articulación más efectiva con actores sociales y un mayor rigor en el ejercicio profesional en los espacios laborales donde impera la dispersión, la confusión y el sistema del capital social sobre la formación o las competencias formales. La cantidad de escuelas con muy distintas concepciones en su currículo de estudios, fortalece la desarticulación (o desorganización) entre centro de estudios, egresados y campos profesionales, lo que tal vez puede verse como variable independiente en la dificultad para articular mejor al campo académico y generar más trabajo en redes.

\section{2. ¿UNA INTERPRETACIÓN MÁS?}

A las interpretaciones que han aparecido para describir y comprender los fenómenos sociales dentro del CAC queremos proponer un nuevo umbral de percepción que llamamos socio-semiótico. El CAC lo podríamos entender como una especie particular de semiosis donde se verifican procesos de producción-distribución-recepción del sentido, activado mediante dispositivos que generación de conocimiento. Uno de ellos, al cual nos referiremos de manera particular, es la generación de referencias y fuentes dominantes para nombrar los objetos, métodos, enfoques que llevan a legitimar y validar a la idea que el CAC entiende por conocimiento.

Partimos del supuesto que las categorías fenomenológicas primeridad-secundaridad-terceridad que son célebremente conocidas desde la semiótica en Peirce, ayudarían a identificar y resaltar procesos de producción de sentido al interior del CaC. A propósito nos hemos valido de la mediación que hace Jensen (1997) a partir de la comunicación social, para aplicar algunas de sus categorías a lo que hemos llamado como CAC. Nos preguntamos con este autor danés, si podemos hablar del CAC como una variedad de semiosis social, es decir un tipo de práctica discursiva en un contexto social determinado. Una determinada forma de reflexividad institucionalizada, la cual produce y hace circular significados sobre la comunicación (mediante objetos, enfoques, orientaciones y métodos), los cuales se relacionan con la práctica educativa, la difusión y divulgación académica, así como otras prácticas (congresos, coloquios, redes, seminarios, revistas, etc.). El CAC deviene en una modalidad de flujo semióti-

Intervención social estratégica. México: Universidad Intercontinental.

Carlos Monsiváis y el campo académico de la comunicación: • I45 Interacción y sentidos 
co, concretado en acciones, las cuales se pueden ver como vinculaciones entre formas de representación y cognición.

$\mathrm{Si}$ es posible pensar esta posibilidad, podemos establecer, siguiendo las célebres categorías fenoménicas de la semiótica en Peirce, los tres constituyentes básicos de su esquema: el elemento de primeridad (asociado a la Posibilidad de Percepción, 'algo', ¿qué?) supondría el estudio de las relaciones sígnicas dadas a través del lenguaje; primeridad del CAC, como condición de posibilidad, vinculado a intereses y deseos de los actores (estudiantes, profesores e investigadores) así como los discursos que generan; estas motivaciones llevan a generar. La secundaridad (asociado a la "actualidad", a los hechos, 'esto', al ¿cómo?) se puede vincular al estudio de la dimensión institucional del CAC, y la manera como los agentes atribuyen significados a las prácticas, fenómenos y discursos; las instituciones poseen ciertas características; es decir, una realidad externa e intersubjetiva, poder coactivo, autoridad moral historia. Esta dimensión estudiaría semióticamente los hechos y objetos que particularizan al CAC. Finalmente, la terceridad (asociada a ley, al pensamiento, y al significado, al ¿por qué?) como elemento para el estudio de los Interpretantes, constituyentes de los efectos de sentido en los actores y agentes; el análisis de las prácticas sociales como actividades de significado o formas de acción social que se recontextualizan como significativas en contextos determinados; la acción de los agentes como formas del significado.

Para Peirce fue importante el estudio de las comunidades institucionalizadas de la ciencia. Las comunidades científicas están sujetas a procedimientos de interpretación pública que determinan lo que se considerará conocimiento científico. Estos mismos procedimientos interpretativos están sujetos a una reformulación a través de la reflexividad de la ciencia. Incluso si las comunidades no poseen atributos esenciales en la forma de una visión superior, autoridad o poder, ellos realizan la función central de desarrollar socialmente y legitimar los principios interpretativos, con objeto de examinar aspectos concretos de la realidad.

Proponemos la idea de ver a Monsiváis como proceso sígnico activado dentro del CAC mediante dispositivos de producción-difusión-interpretación por parte de los agentes del campo. Ello supondría un estudio más completo de lo que perseguimos en estas líneas, donde queremos solamente mostrar una primera idea de un esquema aplicable al estudio de la difusión del conocimiento científico dentro del CaC. Antes de la presentación de dichos dispositivos proponemos una reflexión sobre esta figura singular de la cultura contemporánea mexicana, para ello, en el siguiente apartado hacemos una presentación lo más rápida po-

I46 - Tanius Karam Cárdenas 
sible que caracteriza a este "actante" y objeto de valor dentro del conocimiento científico comunicacional en nuestro país.

\section{ENumeración POR Monsiváis}

Partimos de aceptar en reconocer a Monsiváis (CM) como un autor significativo en el CAC. Con una consistencia identificable que justifica su estudio y referencia en el plano académico, aun cuando él mismo guarda una relación crítica con el mundo universitario. Al margen que él se reconozca parte de esa comunidad, o pueda conocer los valores a los que esa red de interpretantes lo somete, hay un principio sígnico que a la manera de una función puede ser reconocido y vinculado a otra cosa.

Otro elemento de caracterización que nos parece interesante para un enfoque semiótico es la relación que hay en el eje visibilidad-ocultamiento; el caso de nuestro autor, es esa tensión entre quien se confiere como ubicuo y "oculto". Al respecto, Adolfo Castańón lo muestra como alguien "oculto" lo que no resulta casual en contrasentido a su constante presencia pública. La relativa ausencia de trabajos críticos, que apenas recientemente comienzan a aparecen, es un signo de esa contradicción que no deja de llamar la atención para quien es sumamente reconocido. Hay que mencionar que el espacio de esa producción, no es necesariamente el campo de la comunicación. Es en este sentido que decimos como un signo-señal, que se le identifica, no necesariamente se le lee o conoce a profundidad.

Los textos de Monsiváis son reconocidos por una serie de atributos, casi únicos en el periodismo y la literatura mexicana: formas de ironía y humor, registros a varias voces, construcciones de narratarios heterogéneos, listados y enumeraciones, son algunos de estos recursos. En otro trabajo, hemos introducido, en lo general, la enumeración como un recurso que cumple varias funciones: una categoría que agrupa y de manera meta-discursiva señala "estos componentes pertenecen a una misma agrupación cognitiva; que permite el desarrollo del discurso mediante el procedimiento que consiste en acumular expresiones que significan una serie de conjuntos, o bien un conjunto de segmentos (Berinstain, 2000, p. 173). El efecto discursivo que Monsiváis ha logrado con este recurso, es el de una rápida sucesión de imágenes en periodos (que pueden ser más cortos o largos) los cuales invariablemente acumulan verbos. Atributos simples y complejos, se encaden (por ejemplo el conjunto de títulos escritos por un autor) en textos muy densos por sintetizar una gran cantidad de

\section{Carlos Monsiváis y el campo académico de la comunicación: • ${ }^{4} 47$} Interacción y sentidos 
información. Detrás del listado aparentemente didáctico asistimos a un poder ilustrativo, imposible de abarcar en su totalidad en un primer golpe de vista.

La enumeración ofrece una serie de propiedades que al colocarse juntas dan un efecto de complejidad. El enunciador aglutina sus observaciones, su infinita capacidad por el detalle de las acciones y los significados. Los listados en los casos que hemos citado, no proceden por enumeraciones lógicas; es un inventario (semi) completo de aspectos de muy diverso orden que son convocados por el listado mismo y enmarcan las propiedades semánticas de un tópico.

De la misma manera que el propio Monsiváis lo ha hecho, ¿podríamos agrupar los ejes analíticos para la vida-obra monsivaita en un listado paródico?, ¿cómo devendría todo lo "decible", no sólo de la obra, sino de la representación social del autor? Con esta estrategia queremos resumir, lo que hemos tenido oportunidad de detallar en otros lugares (Karam, 2003, 2004, 2005a, 2005b, 2006):

- Niñez y juventud en el marco de una serie de cambios sociales y culturales que trajo la industrialización, el imperio de la radio (1930-1950) rápidamente sustituido por un sucesor aún más poderoso, la TV.

- Fuerte formación religiosa dentro de la heterodoxia protestante, lo que genera desde sus primeros años una clara conciencia de lo que supone la marginalidad en una sociedad unificada política y religiosamente.

- Estudios diversos y con extrańa coherencia en medio de la dispersión: de la economía a la filosofía.

- Relación particular Novo y Benítez a quienes puede reconocer como "maestros oficiales", y los no reconocidos — como el propio Monsiváis lo señala "que ni ellos mismos lo saben", Paz y Fuentes. Si por "maestros" podemos entender su influencia, hay que señalar a Dickens y Twain y Wilde, pero también a Miller y Wolf.

- Relación cercana con los medios universitarios. Llega a Radio UNAM por primera vez en 1953 y comienza a trabajar en ella desde 1960. Es redactor de La hora de los niños y El cine y la crítica.

- Se le considera fundador de la llamada literatura "post-sesenta y ocho". Eclosión en la conciencia del cronista a partir de la masacre de Tlatelolco.

- Autor muy cercano al trabajo de medios impresos y radiales. Escribe crónicas desde 1954; empieza a trabajar para medios universitarios en 1960. Supervisa el programa radiofónico que tuvo el Consejo Nacional de Huelga. Hace paros para El cine y la crítica y es director de Voz Viva de México.

I48 - Tanius Karam Cárdenas 
- Colaborador en prácticamente todos los suplementos culturales de importante en la segunda mitad del siglo xx: Medio Siglo y Estaciones (como secretario de redacción); en el semanario Proceso, la revista Nexos y los diarios Unomásuno, La Jornada, La Cultura en México, México en la Cultura, El Gallo Ilustrado y Personas, dentro de un largo etcétera.

- Autor de imposible obras completas, sólo él ha leído todo lo que ha escrito. El lector de sus crónicas debe conformarse con cinco volúmenes Dias de Guardar (1971), Amor Perdido (1977), Escenas de Pudor y Liviandad (1982), Entrada Libre (1987), Los rituales del caos (1995).

- Prologuista total, en el diccionario hemero-bibliográfico de Aurora Ocampo se consignan más de 100 textos donde se resume la historia cultura y social de México.

- Autor inconfundible de refranes y frases, entre otros: "ya que no tuve niñez, déjenme tener currículum", "o ya no entiendo lo que está pasando o ya no pasa lo que estaba entendiendo", "recuerdo ahora, con esa portentosa memoria que lo inventa todo", "los mexicanos aprendemos a ser mexicanos a través del cine", "la ciudad de México es sobre todo, demasiada gente".

- Único en poder hablar y escribir sobre cualquier tema: Novo, Villaurrutia, Fuentes, Vallejo, Rulfo, Lezama Lima, Siqueiros, Buñuel pero también Luis Miguel, Juan Gabriel, las Flans, Pedro Infante, María Felix, El Niño Fidencio. Hay que sumar las formas de la religiosidad popular, descripción de modos y conductas en la masa, crítica a formaciones políticas dogmáticas (izquierdas y derechas), el uso de malas palabras en el teatro de los setenta, la historia del muralismo mexicano, las formas del liberalismo del siglo xIx, historia cultural mexicana resumida (para perezoso), entre otros temas.

- Cinéfilo, audio-filo y televidente empedernido. Se dice que en sí mismo es una agencia de prensa y sus amigos cercanos (como Sergio Pitol) no dudan en darle la corona a la mejor memoria poética, literaria y audiovisual del país.

- Coleccionista de muñequitos, pancartas, litografías y una extensa cantidad de diplomas que tiene ubicado en el mejor lugar de su casa: apilados en la bañera; coleccionista también de portadas de disco, videocasetes VHs, fotos en color sepia, mapas de la ciudad de México de los siglos XVI y XVII, así como caricaturas sobre sí mismo.

- Poseedor del único certificado probado de ubicuidad: se dice que un día estaba simultáneamente en las exequias del poeta Jaime Sabines, y 
departiendo una conferencia en el teatro Blanquita sobre las formas de la farándula mexicana.

- Posee entre otros títulos y grados: acompañante oficial de María Felix al funeral de Cantinflas; testigo de honor en los contratos discográficos de Juan Gabriel; "pica-ombligos oficial" del grupo las Flans, doble exclusivo en videos sobre boleros de Luis Miguel, y Doctor "honoris causas perdidas (probables e improbables)" conferido por la comunidad universitaria de la Universidad Autónoma de la Ciudad de México (mayo 2008).

Este largo etcétera, tan interminable como su propia obra, puede dar elementos para la reflexión como la de que él mismo, ha conformado una "sub-clase" para estudiar la relación entre la actividad intelectual y los medios masivos, ${ }^{4}$ aunque resulta difícil pensar que ésta sea la causa principal por la que aparece como una referencia legítima al campo de la comunicación.

\section{Y DE Dispositivos, MOdOS DE PRESENCIA Y OTRAS COSAS...}

Hemos intentado una caracterización del campo académico y del mismo Monsiváis. Lo anterior tiene pertinencia para uno de los objetivos particulares de este ensayo: proponer a autores que se conocen o estudian como figuras de referencia (dominante o marginal) en la dinámica del flujo en tanto procesos de significado en una práctica institucional. Lo que ahora podemos mencionar sobre Monsiváis, puede ser un ejercicio, que de hecho ha intentado la Red de Estudios en Teorías de Comunicación (REDECOM) (Galindo et al., 2005), sobre cualquier autor, al ser descrito como un actante dentro del sistema semiótico. Ese juego de referencias aparece como una constelación a estudiarse en distintos dispositivos que activan el sentido a través de su en currículos, bases de datos, libros de textos, portales electrónicos, referencias bibliográficas, que son justamente esos dispositivos que condensar o difunden el significado y el sentido en la acción de producción de conocimiento.

\footnotetext{
${ }^{4}$ A la tipología del crítico voraz a la manera que lo fuera Wright Mills, el pragmatismo funcional (como Octavio Paz), o las legiones de nuevos intelectuales light (donde el anglicismo se traduce más como pret-a-porter, superficialidad, aunque lo implique), supone una forma de organicidad, Monsiváis erige un nuevo sistema de relación, forma de hibrides y yuxtaposición en una doble línea que forma una ética literaria como ese doble movimiento: tensión irresoluble entre el pesimismo estructural versus un optimismo cívico y contracultural incapaz de negarse a sí mismo, o renunciar totalmente a las causas que ha narrado.
}

I $50 \cdot$ Tanius Karam Cárdenas 
Queremos responder a una pregunta básica sobre el modo de presencia y cómo el CAC se apropia Monsiváis al interior de las prácticas de producción social del significado de la comunicación (mediática y cultural). 'Monsiváis' es visto así como una corriente sígnica, una cadena semiótica o sistema de relaciones establecidas por ciertos dispositivos legitimados como tal por el CAC. A Monsiváis se le asocia a objetos y referencias, lo cual no necesariamente funciona como algo estable, porque el Monsiváis de los currículos es diferente, como veremos al aparecido en bases de datos o bien citado por los investigadores.

Para indagar sobre los modos de presencia de Monsiváis en tanto relaciones signicas, acudimos a bases de datos (4.1), planes de estudio, tesis y portales como recursos para preguntar aspectos y especificidades de su presencia.

\section{I. Monsiváis en el CCDOC y nota del autor sobre el CAC}

El Catálogo de Documentación en Ciencias de la Comunicación (CCDOC) es un esfuerzo electrónico como pocos por agrupar el todo de la producción académica de la comunicación en México. Su objetivo principal es consolidar una base de datos bibliográficos, lo más completa, actualizada y orientada a los usuarios que sea posible, sobre la producción científica mexicana en el campo académico de la comunicación y ponerla a disposición de la consulta pública mediante la tecnología informática más avanzada. Es por mucho el esfuerzo más integrado y completo que su autor ha publicado en forma impresa (Fuentes Navarro, 1988, 1995, 2003) y eso en sí mismo merece el más señalado reconocimiento.

Desde el punto de vista semiótico (Chandler, 2001), podemos aplicar tres funciones signicas a esta base (y de hecho a cualquier dispositivo semiótico de producción-difusión de sentido: valor indicial, porque nos señala los aspectos de la producción académica (no porque esté todo lo que debe estar, sino porque pretende abarcarlo todo), valor señalético, de tendencias, modos, métodos, objetos; finalmente, valor simbólico, por su densidad semántica y representacional.

$\mathrm{Al}$ indagar por el signo-descriptor Monsiváis, en el campo autor ${ }^{5}$, aparecen

${ }^{5}$ Este es un concepto que para la teoría crítica literaria no es tan transparente; y las tendencias apuntan a caracterizarlo como una figura: más que un referente empírico de una persona, una red de relaciones, una posición en un campo, etc. Foucault hace una caracterización sugerente en su célebre discurso inaugural para el Colegio de Francia (1999, p. 32), también Barthes (1987, pp. 65-71) ha cuestionado la existencia de una idea monolítica para designar lo idea convencional del autor. Para nuestro propósito vale considerar a un autor del CAC, como algo más que juicios pronunciador por un sujeto empírico. Nos importan, los efectos de realidad que por el argumento de autoridad se despliegan y el vínculo entre cognición, representación y acción que pueda reconocerse. Los dispositivos que analizamos son bases de datos, planes y programas de

Carlos Monsiváis y el campo académico de la comunicación: • I 5 I Interacción y sentidos 
22 entradas (véase, Cuadro 1), índices en la dinámica del flujo generado por el conocimiento campo de la comunicación. La primera observación es que dentro de las obras del propio Monsiváis, solamente se considera Aires de familia, dedicado íntegramente a aspectos culturales más amplios; este sesgo es interesante. Los textos de Monsiváis aparecen reconocidos como propios del campo en las distintas revistas de difusión y divulgación, así como capítulos en libro (por editoriales académicas) o bien textos directamente sobre los medios en su relación con aspectos políticos y culturales.

\section{CuAdro I}

\section{Entrada Monsiváis en CCDOC}

\begin{tabular}{|c|c|c|c|}
\hline Año & $\begin{array}{l}\text { Título / Ficha } \\
\text { (se incluye lugar solo cuando } \\
\text { es fuera de México) }\end{array}$ & $\begin{array}{l}\text { Tipo de } \\
\text { doc. }\end{array}$ & Observaciones \\
\hline I975 & $\begin{array}{l}\text { "Y todo el mundo dijo } \\
\text { 'gulp'. Notas en torno a } \\
\text { los comics". Cuadernos de } \\
\text { Comunicación Núms. } 1 \text { y } \\
\text { 2. Comunicología Aplica- } \\
\text { da de México }\end{array}$ & $\begin{array}{l}\text { Artículo en } \\
\text { revista }\end{array}$ & $\begin{array}{l}\text { Ensayo sobre la historia de los comics, de } \\
\text { los cuales se rescatan el desarrollo del sen- } \\
\text { tido del humor, la oportunidad de atender } \\
\text { al arte popular y la imaginación no deter- } \\
\text { minada pero sí evidente. }\end{array}$ \\
\hline I977 & $\begin{array}{l}\text { "Impresiones sobre la } \\
\text { cultura popular urbana en } \\
\text { México". Cuadernos de } \\
\text { Comunicación Núms. } 21 \\
\text { y } 22 \text { Comunicología Apli- } \\
\text { cada de México }\end{array}$ & $\begin{array}{l}\text { Artículo en } \\
\text { revista de } \\
\text { difusión }\end{array}$ & $\begin{array}{l}\text { Artículo que ubica entre } 1930 \text { y } 1950 \text { la } \\
\text { etapa más fecunda de la cultura popular } \\
\text { urbana en México a través de imágenes so- } \\
\text { bre el teatro y las carpas, el chiste político, } \\
\text { los salones de baile, el cine y la radio }\end{array}$ \\
\hline 1980 & $\begin{array}{l}\text { A ustedes les consta. } \\
\text { Antología de la crónica } \\
\text { en México. México. ERA, } \\
1980\end{array}$ & Libro & Excelente crónica \\
\hline 1982 & $\begin{array}{l}\text { El comic es algo serio. } \\
\text { México. EUFESA }\end{array}$ & Libro & $\begin{array}{l}\text { Se reúnen textos de diverso tipo sobre las } \\
\text { historietas, previamente publicados en la } \\
\text { revista Cuadernos de Comunicación. Hay } \\
\text { apreciaciones "teóricas" y apreciaciones } \\
\text { "prácticas", muchas de ellas realizadas por } \\
\text { mexicanos, país donde se producen entre } \\
90 \text { y } 100 \text { millones de ejemplares mensua- } \\
\text { les de historietas y fotonovelas. }\end{array}$ \\
\hline
\end{tabular}

estudio y los definimos como núcleos de condensación par lo que hemos mencionado como condicionantes del discurso 


\begin{tabular}{|c|c|c|c|}
\hline 1984 & $\begin{array}{l}\text { "La agonía interminable } \\
\text { de la canción romántica". } \\
\text { Comunicación y Cultura } \\
\text { No. 12. UAM Xochimilco. }\end{array}$ & $\begin{array}{l}\text { Artículo en } \\
\text { revista }\end{array}$ & $\begin{array}{l}\text { Este ensayo revisa todo el siglo XX mexica- } \\
\text { no para ilustrar cómo la canción románti- } \\
\text { ca es el grave festejo de las contradicciones } \\
\text { en la canción romántica. }\end{array}$ \\
\hline 1987 & $\begin{array}{l}\text { "El difícil matrimonio } \\
\text { entre cultura y medios } \\
\text { masivos". Chasqui, revista } \\
\text { latinoamericana de comu- } \\
\text { nicación No. 22. CIESPAL. } \\
\text { Ecuador }\end{array}$ & $\begin{array}{l}\text { Artículo en } \\
\text { revista }\end{array}$ & $\begin{array}{l}\text { De acuerdo con las imágenes en uso, un } \\
\text { paisaje apocalíptico donde el segundo de } \\
\text { los términos acosa interminablemente al } \\
\text { primero, degrada sus escasas posibilidades } \\
\text { y concluye en millones de espectadores } \\
\text { como millones de conciencias muertas. }\end{array}$ \\
\hline 1987 & $\begin{array}{l}\text { "La cultura popular } \\
\text { en el ámbito urbano" } \\
\text { CLACSO: Comunicación } \\
\text { y Culturas Populares en } \\
\text { Latinoamérica: FELAFACS/ } \\
\text { Gustavo Gili }\end{array}$ & Capitulo & $\begin{array}{l}\text { Se parte que la vida cotidiana en la ciudad } \\
\text { capitalista es la lucha incesante contra } \\
\text { las versiones disponibles del Estado y } \\
\text { del capital: crisis de los servicios urbanos } \\
\text { (vivienda, transporte, ofertas culturales, } \\
\text { sociales, educativas y de salud), espacios } \\
\text { verdes destruidos por la especulación y la } \\
\text { ignorancia, contaminación, despersonali- } \\
\text { zación, formas de relación humana envile- } \\
\text { cidas y envilecedoras. }\end{array}$ \\
\hline 1989 & $\begin{array}{l}\text { "El genio popular de Ga- } \\
\text { briel Vargas". Libros de } \\
\text { México } 16\end{array}$ & $\begin{array}{l}\text { Capitulo } \\
\text { en libro }\end{array}$ & $\begin{array}{l}\text { Reflexión sobre Vargas y su lugar dentro } \\
\text { de la historia del comic en México. }\end{array}$ \\
\hline 1992 & $\begin{array}{l}\text { "Emilio Fernández, el } \\
\text { Indio. Los sueños de la na- } \\
\text { ción engendran símbolos". } \\
\text { En Intermedio 1. RTC. } \\
\text { SEGOB }\end{array}$ & $\begin{array}{l}\text { Artículo en } \\
\text { revista }\end{array}$ & $\begin{array}{l}\text { Ensayo biográfico acerca del proyecto del } \\
\text { Indio Fernández, sus influencias y catego- } \\
\text { rías morales y, por supuesto, su visión de } \\
\text { México. }\end{array}$ \\
\hline 1992 & $\begin{array}{l}\text { "Las mitologías del cine } \\
\text { Intermedios No. 2: R.T.C. } \\
\text { SEGOB. México. }\end{array}$ & $\begin{array}{l}\text { Artículo en } \\
\text { revista de } \\
\text { difusión }\end{array}$ & Explica aspectos del melodrama en el cine. \\
\hline 1992 & $\begin{array}{l}\text { "Tin Tán. Es el pachuco } \\
\text { un sujeto singular". In- } \\
\text { termedio No. 2: R.T.C. } \\
\text { Secretaría de Gobernación. } \\
\text { México. }\end{array}$ & $\begin{array}{l}\text { Artículo en } \\
\text { revista de } \\
\text { difusión }\end{array}$ & Se explican aspectos de la vida del cómico. \\
\hline 1992 & $\begin{array}{l}\text { "Comunicación, cultura } \\
\text { política y democracia". En } \\
\text { ESTEINOU (ed.): Comuni- } \\
\text { cación y Democracia. } \\
\text { CONEICC }\end{array}$ & $\begin{array}{l}\text { Capítulo } \\
\text { en libro }\end{array}$ & $\begin{array}{l}\text { Se concentra en una versión muy sucinta } \\
\text { de la relación entre los medios de difusión } \\
\text { masiva y la cultura política de orientación } \\
\text { y sentido democráticos. }\end{array}$ \\
\hline
\end{tabular}

Carlos Monsiváis y el campo académico de la comunicación: • I 53 Interacción y sentidos 


\begin{tabular}{|c|c|c|c|}
\hline 1992 & $\begin{array}{l}\text { "Expediente sobre la cen- } \\
\text { sura". Revista Mexicana de } \\
\text { Comunicación. FMB }\end{array}$ & $\begin{array}{l}\text { Artículo en } \\
\text { revista }\end{array}$ & $\begin{array}{l}\text { Reflexión sobre la televisión. Se analiza la } \\
\text { manera como se presenta la censura en los } \\
\text { medios. }\end{array}$ \\
\hline I993 & $\begin{array}{l}\text { "María Félix, pabellón de } \\
\text { la imagen". Intermedios } \\
\text { No. 6: R.T.C. Secretaría } \\
\text { de Gobernación. México. }\end{array}$ & $\begin{array}{l}\text { Artículo en } \\
\text { revista de } \\
\text { difusión }\end{array}$ & $\begin{array}{l}\text { Proporciona algunos elementos para com- } \\
\text { prender la magia y el misterio de los que } \\
\text { María Félix ha sabido rodearse. }\end{array}$ \\
\hline I994 & $\begin{array}{l}\text { "Noticiero del Apocalipsis } \\
\text { y control remoto desde } \\
\text { el sorteo del paraíso". } \\
\text { NÚNEZ y sOLís (comps.): } \\
\text { Comunicación, Identidad } \\
\text { e Integración Latinoameri- } \\
\text { cana. UIA }\end{array}$ & $\begin{array}{l}\text { Capítulo } \\
\text { en libro }\end{array}$ & $\begin{array}{l}\text { Una de las dos conferencias magistrales } \\
\text { con que se abrió el VII de FELAFACS (octu- } \\
\text { bre de 1992). Reflexión sobre las escuelas } \\
\text { de comunicación, mercado de trabajo, etc. }\end{array}$ \\
\hline I994 & $\begin{array}{l}\text { "La cultura popular en el } \\
\text { ámbito urbano: el caso de } \\
\text { México" En HERLINGHAUS } \\
\text { y WALTER (Eds.): Posmo- } \\
\text { dernidad en la periferia. } \\
\text { Langer Verlag. Alemania }\end{array}$ & $\begin{array}{l}\text { Capítulo } \\
\text { en libro }\end{array}$ & $\begin{array}{l}\text { Se define lo popular en el espacio urbano, } \\
\text { para después trabajar la especificidad de } \\
\text { la cultura urbana. El autor establece las } \\
\text { diferencias y similitudes entre lo popular, } \\
\text { lo urbano y lo rural. }\end{array}$ \\
\hline 2000 & $\begin{array}{l}\text { Aires de familia. Cultura y } \\
\text { sociedad en América Lati- } \\
\text { na. Anagrama. Espala }\end{array}$ & Libro & $\begin{array}{l}\text { Este ensayo es una aproximación a cam- } \\
\text { bios y permanencias de la cultura latinoa- } \\
\text { mericana en el siglo XX, en un panorama } \\
\text { que va del culto a los héroes a la sociedad } \\
\text { del espectáculo, de las migraciones cul- } \\
\text { turales a la influencias de Hollywood en } \\
\text { las sociedades en penumbras, del canon } \\
\text { literario al idioma televisivo, de la fe devo- } \\
\text { cional a los proyectos democráticos. }\end{array}$ \\
\hline 2000 & $\begin{array}{l}\text { "El debate y el uso de la } \\
\text { crítica" SOLÍS (Coord.): } \\
\text { Medios de comunicación } \\
\text { y procesos electorales. Un } \\
\text { compromiso para el futuro. } \\
\text { RTC }\end{array}$ & $\begin{array}{l}\text { Capitulo } \\
\text { en libro }\end{array}$ & $\begin{array}{l}\text { El autor da cuenta del debate del } 25 \text { de } \\
\text { abril del } 2000 \text {, cuyos participantes fueron } \\
\text { los candidatos postulados a la presidencia } \\
\text { de la República, en el que se evidenció, el } \\
\text { poderío de los medios electrónicos. }\end{array}$ \\
\hline 2002 & $\begin{array}{l}\text { "'Si no compra no predi- } \\
\text { que’ Una crónica de los } \\
\text { comunicadores sociales en } \\
\text { América Latina” Diálogos } \\
\text { de la Comunicación No. } \\
\text { 65. FELAFACS, Perú }\end{array}$ & $\begin{array}{l}\text { Artículo en } \\
\text { revista }\end{array}$ & $\begin{array}{l}\text { La carrera descubre una nueva zona de } \\
\text { ilusiones y realidades laborales y, de paso, } \\
\text { instala el vocablo que es piedra de toque } \\
\text { de la credulidad y la credibilidad, fuera y } \\
\text { dentro de los ámbitos universitarios. }\end{array}$ \\
\hline
\end{tabular}




\begin{tabular}{|l|l|l|l|}
\hline 2002 & $\begin{array}{l}\text { "El melodrama: 'No te } \\
\text { vayas, mi amor, que es } \\
\text { inmoral llorar a solas" } \\
\text { HERLINGHAUS (ed.). Na- } \\
\text { rraciones anacrónicas de la } \\
\text { modernidad. Melodrama e } \\
\text { intermedialidad en Amé- } \\
\text { rica Latina. Chile. Cuarto } \\
\text { Propio }\end{array}$ & $\begin{array}{l}\text { Capitulo } \\
\text { en libro }\end{array}$ & $\begin{array}{l}\text { Este ensayo parte de que tan importante } \\
\text { como la historia del melodrama, aunque } \\
\text { mucho menos estudiada, es la historia de } \\
\text { su público en América Latina. A lo largo } \\
\text { de dos siglos, las generaciones sucesivas } \\
\text { obtienen del melodrama lo básico de su } \\
\text { educación sentimental y del idioma ade- } \\
\text { cuado para las pasiones. }\end{array}$ \\
\hline $\begin{array}{l}\text { Los medios en peligro" } \\
\text { Signo y Pensamiento No. } \\
\text { versidad Javeriana }\end{array}$ & Articulo & $\begin{array}{l}\text { Este es el texto de una ponencia presen- } \\
\text { tada por Monsiváis en la Conferencia } \\
\text { Internacional Los medios informativos } \\
\text { en peligro, en Bogotá, el 22 de marzo de } \\
\text { 2002. }\end{array}$ \\
\hline $\begin{array}{l}\text { "Función corrida (el cine } \\
\text { mexicano y la cultura } \\
\text { popular urbana)" VALEN- } \\
\text { ZuELA ARCE (coord.): Los } \\
\text { estudios culturales en Méxi- } \\
\text { co. CONACULTA }\end{array}$ & $\begin{array}{l}\text { Capitulo } \\
\text { en libro }\end{array}$ & $\begin{array}{l}\text { El público de vanguardia en rigor no } \\
\text { existe, y en su conjunto el cine mexicano } \\
\text { de un periodo, la Época de Oro del cine } \\
\text { mexicano, es cultura popular, porque } \\
\text { unifica en sus espectadores la idea básica } \\
\text { que tienen de sí mismos y de sus comuni- } \\
\text { dades, y consolida actitudes, géneros de la } \\
\text { canción, estilos del habla, lugares comunes } \\
\text { del lirismo o la cursilería, las tradiciones a } \\
\text { las que la tecnología alza en vilo, a todo lo } \\
\text { que permite la pantalla. }\end{array}$ \\
\hline
\end{tabular}

El solo hecho de una mirada detenida a este listado arroja alguna información. Su primer rasgo es su variedad. En cuanto al objeto "medios de comunicación" la reflexión más frecuente es aplicada al cine y los medios impresos (de manera particular prensa, comics). Monsiváis ha escrito textos sobre el melodrama y la modernidad, las tensiones entre cultura popular y medios, descripción de las mutaciones culturales, entre otros, que constituyen un eje central en su presencia dentro de este listado. Dentro de las fuentes hemerográficas, nos llama la atención la presencia que tiene en Revista de Comunicación que impulsara del grupo Ferrer, pero también en ejemplares de Diálogo, Signo y Pensamiento y Revista Mexicana de Comunicación que son centrales en el campo latinoamericano de la comunicación. Estos textos nos permiten corroborar la presencia estable asociada a dos ejes semánticos fundamentales: el periodismo y los estudios sobre la cultura, los cuales se alternan o cargan de acuerdo al contexto y al dispositivo ya que el primero por ejemplo, puede asociarse la libertad de expresión, lucha contra el poder; y el segundo, lo mismo 
de reflexiones amplias sobre la cultura popular, que crónica sobre algún efecto específico dentro de una práctica cultural.

Por problemas de espacios, solamente hacemos un breve comentario, sobre un texto, que para los objetivos de este ensayo, nos ha llamado la atención. Se trata del que aparece en la revista Diálogos (2002) y donde Monsiváis refiere sus intuiciones sobre la comunicación académica y confirma en su particular estilo algunos de los rasgos que hemos mencionado arriba como su masividad (en la que parece sustentarse su legitimación) y desarticulación; sin embargo, no aborda únicamente el problema vocacional del profesional en la comunicación, sino que abunda en otros fenómenos sugerentes en su reflexión. Lo interesante de este artículo, es que es uno de los pocos trabajos donde el autor realiza esa mirada crítica y ácida.

En el texto, el autor de Días de guardar, entrevé la dimensión instrumental, identifica el tránsito del periodista al "comunicador-comunicólogo"; reconoce a la profesión como heredera de esas otras actividades que en realidad servían para agrupar toda vocación posible, sin mucha definición. Una línea interesante para estudiar se desprende del "licenciado", al "sociólogo" y ahora, todo parece detenerse o rematar en el "comunicólogo". Sobre el sufijo, no le interesa hacer matices científicos; simplemente acepta el pobre estatuto de reflexión y análisis sin que profundice en las causas de ellos. En su agrupación de este doble sustantivo viscoso, reconoce algunos escenarios laborales, sobre los cuales parodia.

De mayor interés cultural es la relación que hace entre modernidad e imagen, en el valor total de nueva retórica y el exceso en su confianza que colinda con la forma de una nueva religión. Es cierto que en este artículo no profundiza sobre cómo la globalización o las nuevas tecnologías puedan transformar el perfil de esa figura sustantivizada amante de lo público y de la imagen funcionalizada. El artículo concluye primero con una rápida visita al fenómeno del Big brother (como gran fenómeno inmediato al momento de escribir el texto), al que se sigue un listado de nuevos temas donde se prevén las tensiones entre lo local-global, la idea del profesional de la comunicación como alguien, que o bien analiza los rituales cotidianos en la sociedad de la información, o sencillamente cree que dice algo diferente, cuando en realidad repite lo dicho por otros.

En su reflexión, no deja de darse esta polaridad entre la "Cultura" letrada y la "cultura” como pauperización. Hay en la comunicación académica un enigma entre estos dos tipos que se coquetean y al hacerlo, se acercan y alejan, en lo que parece ser una visión doble de un profesional masificado y la posibilidad de un crítico cultural con cierta autonomía en su pensamiento.

I $56 \cdot$ Tanius Karam Cárdenas 


\subsection{Planes, programas de estudio}

Los planes y programas de estudio son constituyentes de la recepción que elaboran los diseñadores quienes bajo una perspectiva, establecen contenidos, propósitos, temas y bibliografías. El "programa de estudio" funciona como un dispositivo que configura un ideal de profesional de la comunicación. Los planes y programas son constituyentes y mecanismos semióticos generadores de conocimiento y prácticas, al menos en cuanto ayudará (o no) a un tipo de interacción en el aula y la generación de una actitud. Los planes de estudio ayudar a definir el perfil en el cual la referencia "Monsiváis" enmarca un elemento del tipo ideal: inscribirlo en cursos de periodismo o sociología, supone una elección que enmarca al autor como referencia legible y legítima en un marco de agrupaciones como puede ser un programa de estudio. Al carecer de una base de datos en plantes y programas, no hemos tenido otro recurso que Internet para buscar esta información.

En la UNAM, dentro de la licenciatura en Ciencias de la Comunicación (versión 1997), aparece en la materia Taller de Periodismo Especializado (70 semestre) Los Rituales del Caos, como bibliografía complementaria. En la materia optativa, "Sociología del Cine" ( $7^{\circ}$ y $9^{\circ}$ semestre) se citan dos artículos que aparecen referidos también en la base de CCDOc Emilio Fernández El Indio (en Intermedios no. 1, mar-abr 1992) y Las mitologias del cine mexicano (en Intermedios no. 2, jun-ago 1992).

En la ENEP Aragón, dentro de su Licenciatura en Comunicación y Periodismo (plan 1993), en el $2^{\circ}$ semestre, en la asignatura Nota informativa y crónica noticiosa se refiere a la antología $A$ ustedes les consta; en el $4^{\circ}$ semestre, en Reportaje aparece la misma referencia. En $5^{\circ}$ semestre, en Teoría y medios de comunicación III se cita Amor perdido, así como Notas sobre la cultura mexicana en el siglo XX en Historia General de México (Colmex, 1977), lo cual nos parece una rareza, que en un curso aparezca como referencia un libro de crónicas-ensayos y un ensayo sobre la historia cultural mexicana. En el $6^{\circ}$ semestre, Seminario-Taller Prensa I (materia optativa) se cita un artículo en periódico, Autoinquisición de Monsiváis (en unomásuno, 19 de febrero de 1989, pp 1-23). En el séptimo en la asignatura Estilos periodísticos y literarios, CM aparece como tema III, denominado Estilos en el periodismo de opinión: 3.2. La heterodoxia en el estilo: 3.2.3. Carlos Monsiváis, se citan dos libros de crónicas-ensayos (Amor perdido y Entrada Libre). En el $7^{\circ}$ semestre, dentro del Seminario-Taller Prensa II (Materia optativa) se cita la antología $A$ ustedes les consta y Días de guardar.

En el caso de la UAM-Xochimilco dentro de su licenciatura en Comunicación

Carlos Monsiváis y el campo académico de la comunicación: • I 57 Interacción y sentidos 
Social (2002), en el Módulo TCIII, Escritura y Comunicación - Periodismo (Teoría), en su taller de periodismo encontramos $A$ ustedes les consta. En el Módulo TC/8, Cinematografía y Procesos Culturales - Producción Audiovisual I (Fase teórica) se cita $A$ través del espejo, libro poco referido sobre el cine mexicano en su relación con el público.

Finalmente, en otro caso de universidad pública, dentro de la licenciatura en comunicación y cultura, en una de las primeras versiones del plan de estudios aparece citados Días de Guardar y Entrada libre; en otra versión más reciente se refiere su antología de crónica.

En suma podemos decir que para el CAC, en cuanto sus planes y programas, Monsiváis es autor de textos que ayudan a periodistas en la identificación de usos del lenguaje vinculados a herramientas para este ejercicio. En el mejor de los casos, su presencia es central por algunos textos de crónicas-ensayos. Por ejemplo no hemos visto referido Escenas de pudor y liviandad, sus crónicas biográficas u otros tipos de ensayos que lo mismo podría ser ilustrativos dentro de los objetivos que se persiguen.

En cierto que esta primera mención no tiene valor para pensar en una afirmación general. Hemos tenido al alcance del ensayo, planes de universidades públicas, las tres que lo imparten dentro del Valle de México. Hay que recordar que hay más de 350 escuelas de comunicación en el país, donde también podemos ver usos muy diversos.

\subsection{Tesis}

La tesis es un tipo de trabajo académico que remite a un sentido lógico: la argumentación a favor de una afirmación, la cual se pretende probar o al menos ofrecer elementos para su aceptación. La tesis es un dispositivo vinculado a la formación de profesionales del área y también un generador de saberes y acciones, de estructuras que a un nivel actualizan representaciones. Un signo importante es el tesista, quien ha escogido dentro de un extenso umbral posible, un tema, el cual revela más que interés por lo que una elección entre otras opciones supone. No es aquí el lugar para emitir un juicio sobre los trabajos, sino señalar cómo la tesis, semióticamente, está en lugar de un interés o un tema que la institución y el sustentante consideran pertinente y que de hecho han sancionado favorablemente, toda vez que siempre la referencia a tesis, es de trabajos aprobados.

$\mathrm{Al}$ margen del debate sobre las tesis como índice efectivo para verificar si el sustentante posee dichas competencias, notamos en primer lugar, la escasa

I $58 \cdot$ Tanius Karam Cárdenas 
presencia de trabajos de tesis de licenciatura en escuelas de comunicación: hemos encontrado tres trabajos en el marco de escuelas de comunicación (1 en la Escuela de Periodismo Carlos Septién y dos en la red de escuelas superiores de la UnAM). Por lo que a esta información se refiere, podríamos concluir que Monsiváis es un autor más pertinente para el campo literario o de estudios latinoamericanos que propiamente para la comunicativa, y dentro de ésta, principalmente la dimensión más periodística del autor; su vínculo es más estrecho a la representación del periodista.

En cuanto al grado, podemos hacer una mención: para las tres tesis producidas desde el CAC, son de licenciatura. No hemos encontrado tesis de postgrado en escuelas de comunicación. Por el contrario, en EE.Uu. — donde no se tiene que realizar tesis en el pregrado (o bachelor degree)—, todas las tesis son de doctorado y se vinculan al estudio de la cultura, o de la literatura en su relación a este espacio semántico.

En el Cuadro 2, resumimos el resultado de esta indagación y precisamos otro índice de su presencia en el CAC, el cual se vincula a su producción periodística principalmente. Este enunciado general tendría que confrontarse con un análisis más detallado y riguroso que compare estos trabajos. Si bien suponemos en el trabajo de Arellano y Piliado un nivel de generalización por el título, llama la atención que los trabajos encontrados sean de pregrado en comunicación, y parezcan establecer a un nivel amplio, como figura reconocida. También llama la atención que la mayor parte de los trabajos no se encuentren ubicados dentro de los estudios de periodismo o comunicación. Monsiváis, nos parece sigue con una presencia más sostenida y una preocupación más analítica en el campo de los estudios literarios, como un referente aún más identificable del que tal vez pueda tener en la comunicación.

Cuadro 2.

Tesis sobre Monsiváis

\begin{tabular}{|l|l|l|l|l|}
\hline Autor & Año & Titulo & $\begin{array}{l}\text { Facultad, área e } \\
\text { Institución }\end{array}$ & Grado \\
\hline $\begin{array}{l}\text { Arellano Becerril, } \\
\text { José Vidal }\end{array}$ & I983 & $\begin{array}{l}\text { Carlos Monsiváis: } \\
\text { testimonio de periodismo } \\
\text { de vanguardia. }\end{array}$ & $\begin{array}{l}\text { Escuela de } \\
\text { Periodismo Carlos } \\
\text { Septién }\end{array}$ & Licenciatura \\
\hline $\begin{array}{l}\text { Gudiño } \\
\text { Domínguez, } \\
\text { María de }\end{array}$ & I99I & $\begin{array}{l}\text { Carlos Monsiváis y su } \\
\text { multifacético talento. }\end{array}$ & $\begin{array}{l}\text { Lengua y Literatura } \\
\text { Hispánica. UNAM }\end{array}$ & Licenciatura \\
\hline
\end{tabular}

Carlos Monsiváis y el campo académico de la comunicación: • I 59 Interacción y sentidos 


\begin{tabular}{|c|c|c|c|c|}
\hline $\begin{array}{l}\text { Munguía Salazar, } \\
\text { Abel. }\end{array}$ & I998 & $\begin{array}{l}\text { El ensayo y la crónica, } \\
\text { géneros por excelencia en } \\
\text { el manejo de la cultura } \\
\text { popular en los escritos } \\
\text { periodistas mexicanos : } \\
\text { José Agustín, Carlos } \\
\text { Monsiváis, Cristina Pacheco } \\
\text { y Elena Poniatowska }\end{array}$ & $\begin{array}{l}\text { Licenciado en } \\
\text { Comunicación y } \\
\text { Periodismo } \\
\text { ENEP.- Aragón }\end{array}$ & Licenciatura \\
\hline $\begin{array}{l}\text { Pérez Ortiz } \\
\text { Melanie Ann }\end{array}$ & 1999 & $\begin{array}{l}\text { Between lettered, popular, } \\
\text { and mass cultures: } \\
\text { Intellectuals and the } \\
\text { public sphere in Mexico } \\
\text { and Puerto Rico. A } \\
\text { reading of the works } \\
\text { of Carlos Monsivais, } \\
\text { Cristina Pacheco, Edgardo } \\
\text { Rodríguez Julia and Ana } \\
\text { Lydia Vega. }\end{array}$ & Stanford University, & Doctorado \\
\hline Egan Linda & $200 \mathrm{I}$ & $\begin{array}{l}\text { Carlos Monsiváis: } \\
\text { culture and chronicle in } \\
\text { contemporary Mexico }\end{array}$ & $\begin{array}{l}\text { Universidad de } \\
\text { California Estudios } \\
\text { Mexicanos }\end{array}$ & Doctorado \\
\hline $\begin{array}{l}\text { Díaz de Gallegos } \\
\text { Gabriela }\end{array}$ & $200 \mathrm{I}$ & $\begin{array}{l}\text { From the lettered } \\
\text { city to the televised } \\
\text { city: modernity and } \\
\text { globalization in the essays } \\
\text { of Carlos Monsiváis }\end{array}$ & $\begin{array}{l}\text { The University of } \\
\text { New Mexico, USA }\end{array}$ & Doctorado \\
\hline $\begin{array}{l}\text { Maracara } \\
\text { Martínez, Carmen } \\
\text { Isabel }\end{array}$ & $200 \mathrm{I}$ & $\begin{array}{l}\text { Intertextualidad, } \\
\text { subalternidad e ironía: la } \\
\text { obra de Carlos Monsiváis }\end{array}$ & $\begin{array}{l}\text { Departamento de } \\
\text { Filología Española. } \\
\text { Universidad } \\
\text { Autónoma de } \\
\text { Barcelona. } \\
\end{array}$ & Doctorado \\
\hline $\begin{array}{l}\text { Flores Ramírez } \\
\text { Navidad }\end{array}$ & 2002 & $\begin{array}{l}\text { El espectáculo reflejo del a } \\
\text { realidad mexicana. Escenas } \\
\text { de Pudor y Liviandad. } \\
\text { Carlos Monsiváis. }\end{array}$ & $\begin{array}{l}\text { Facultad de } \\
\text { Filosofía, UNAM } \\
\text { (Licenciada en } \\
\text { literatura y letras } \\
\text { hispánicas) } \\
\end{array}$ & Licenciatura \\
\hline $\begin{array}{l}\text { Karsten Glup } \\
\text { Adriana Marianne }\end{array}$ & 2002 & $\begin{array}{l}\text { Crónica de una } \\
\text { convergencia. Días de } \\
\text { guardar y la rebelión de los } \\
\text { maniquíes }\end{array}$ & $\begin{array}{l}\text { Literatura } \\
\text { Latinoamericana. } \\
\text { Universidad } \\
\text { Iberoamericana } \\
\end{array}$ & Licenciatura \\
\hline $\begin{array}{l}\text { Guízar Álvarez, } \\
\text { Eduardo }\end{array}$ & 2002 & $\begin{array}{l}\text { Literatura posnacional } \\
\text { en México: parodia, } \\
\text { reescritura, reinvención }\end{array}$ & $\begin{array}{l}\text { The University of } \\
\text { Iowa }\end{array}$ & Doctorado \\
\hline
\end{tabular}

ı60 - Tanius Karam Cárdenas 


\begin{tabular}{|l|c|l|l|l|}
\hline $\begin{array}{l}\text { Piliado Navia, } \\
\text { Leonardo David. }\end{array}$ & 2002 & $\begin{array}{l}\text { Carlos Monsiváis: 30 años } \\
\text { de vida intelectual }\end{array}$ & $\begin{array}{l}\text { Licenciado en } \\
\text { Periodismo y } \\
\text { Comunicación } \\
\text { Colectiva } \\
\text { ENEP- Acatlán }\end{array}$ & Licenciatura \\
\hline $\begin{array}{l}\text { Salazar Escalante, } \\
\text { Gilberto Jezreel }\end{array}$ & 2003 & $\begin{array}{l}\text { La ciudad como texto: La } \\
\text { crónica urbana de Carlos } \\
\text { Monsiváis }\end{array}$ & $\begin{array}{l}\text { Facultad de } \\
\text { Filosofía y Letras. } \\
\text { UNAM. México } \\
\text { (Licenciatura } \\
\text { en Estudios } \\
\text { Latinoamericanos) }\end{array}$ & Licenciatura \\
\hline
\end{tabular}

\subsection{Portales de comunicación}

Los portales se han convertido en recursos importantísimos para la divulgación del saber. Son mecanismos de significación y van adquiriendo una presencia importante en las comunidades académicas y su papel en las formas de organización. En México, donde carecemos de bibliotecas, bases de datos y centros de información (con las contadas excepciones del CCDOC), Internet, es algo más que un recurso menor o secundario. Se convierte no sólo en fuente, sino en dispositivo para la creación de conocimiento. En cuanto revistas, son muchas más las que se pueden encontrar vía electrónica en Internet, que aquellas impresas ubicadas en los anaqueles de las bibliotecas. Si consideramos que la inmensa mayoría de los estudiantes de comunicación se encuentran en universidades privadas, y no tienen servicios bibliotecarios de alta calidad (salvo excepciones, como el sistema de bibliotecas de la UIA o ITESM) o acceso a bases electrónicas internacionales, el Portal se convierte en otro condensador importante en esas redes, grupos y creación de conocimiento, está deviniendo en un recurso didáctico importante para diversos cursos.

Consideramos al Portal como otro dispositivo semiótico para indagar por los índices de la presencia monsivaíta en el CAC; para ello hemos indagado en dos portales en castellano que consideramos más importantes: Portal de Comunicación, hospedado en la Universidad de Málaga y el Portal del INCOM, de la Universidad Autónoma de Barcelona. ${ }^{6}$ En los buscadores propios de los portales hemos preguntado el descriptor "Monsiváis".

En el primero de ellos, "Portal de Comunicación" encontramos cinco entradas: "Del terrorismo y sus víctimas" (en Sala de Prensa, 627) y "La caricatura

${ }^{6}$ Las referencias son, INFOAMERICA, ubicado en http://www.infoamerica.org/; el Portal del INCOM de la Autónoma de Barcelona se ubica en: http://www.portalcomunicacion.com/esp/home.asp 
periodística y de paz", dossier donde varios autores (entre ellos Monsiváis) disertan sobre la visualización de la caricatura en el tema (también ubicado originalmente en Sala de Prensa); "Lucha contra los poderes invisibles" (aparecido originalmente en el $\mathrm{N}^{\circ} 86$ de la Revista Mexicana de Comunicación) donde presenta un perfil del periodista Manuel Buendía y la manera como supo tomar distancia de los poderes reales e invisibles. De la también conocida revista $E t$ cétera, aparece en el portal "Que se lleven sus matanzas a otra parte que no me dejan ver la telenovela”, artículo que como casi todos los aparecidos en este portal tiene como eje al periodismo en situación de amenaza, de manera particular por el terrorismo y la violencia. Resulta interesante que este buscador interno del Portal haya arrojado textos de una relativa consistencia temática periodística, con una sola excepción, la cita que realiza Mattelart en una entrevista sobre la relación intelectuales y medios masivos, donde alude a Monsiváis (a quien llama "periodista" y "teórico mexicano") a través de una de sus recurrentes frases, "la globalización significa que usted nunca más tendrá que pedir disculpas”. El que Mattelart, teórico canonizado, use en su línea argumental, para mostrar las formas de engaño que hay en la globalización. Interesante que uno de los principales "teóricos" de la comunicación, confiera ese estatuto a Monsiváis, quien es ciertamente reconocido como una figura para pensar los medios y la cultura, pero nada más distante a la propia percepción de Monsiváis.

En el caso del portal del INCOM, hemos encontrado 4 entradas que tiene, como se presenta, otra consistencia: en primer lugar, una comunicación en congreso de la Dra. Cecilia Cervantes, sobre políticas de comunicación y políticas culturales. Monsiváis aparece referido a su crítica de la visión cultural que tenía el régimen de Fox; la cita del autor es de una entrevista informativa en el diario Reforma, también referida contra la propuesta de la "Mega-Biblioteca José Vasconcelos". En segundo lugar, una ponencia sobre el cine mexicano y la picaresca urbana que presenta Luis Javier Arango en el marco de un congreso académico. En esta ponencia cita de Monsiváis la idea que la representación del mexicano y de lo mexicano es inherente al cine nacional.

Este esquema se completa con dos entradas de una autora muy cercana a Monsiváis, como es Rossana Reguillo, en una ponencia y en una lección del Portal. En la ponencia recuerda la actitud "pesimista" sobre el papel de los medios y como han sustituido a otras instituciones sociales para hacer ciertas funciones. En la lección de estudio, que forma parte de una importante colección de textos didácticos ubicados en el portal, la autora jalicinense, presenta las bases de los "Estudios Culturales", refiere como Monsiváis no se sentiría muy cómodo con

I62 - Tanius Karam Cárdenas 
el epíteto de "culturalista" y señala sobre todo, la importancia de los trabajos que muestran a la cultura en su relación con el poder.

De estos dos portales aparece un rasgo diferenciador: el elemento semántico más vinculado a la acción periodística en INFOAMERICA, la cual sobre todo quiere mostrar sus vínculos con el poder y sus abusos; por su parte para INCOM es una perspectiva más cultural en INCOM. El usuario de estos portales encontrará estas orientaciones que o bien reforzará la imagen ya existente, por medio de sus cursos, profesores o visibilidad social (de manera particular en México). Quedan por precisar estos dispositivos y analizar otros, como las referencias que realizan los propios investigadores y lo que de Monsiváis, citan, refieren o confrontan.

\section{Cierre}

Podemos concluir el eje en el que Monsiváis como autor se mueve en un eje que va de lo estrictamente periodístico como lenguaje a lo cultural en tanto reflexión sobre los medios y la cultura en general. No siempre asistimos a reflexiones sobre el estilo o discurso, ni tampoco un análisis detallado sobre sus recursos discursivos, esta parte parece preocupar menos a los investigadores de la comunicación. En una ocasión Zaid llegó a mencionar que el destino de este nuevo profesional serían los suplementos culturales. Antes que éstos inundaran, o que las escuelas proliferaran, como el big-bang, Monsiváis ya estaba ahí, en citas y parodias, en la doble mirada hacia los medios, en una relación menos lineal con esas industrias que no siempre critica.

En este ensayo hemos querido demostrar, el que sea reconocido Monsiváis, no significa que sea conocido. Esta afirmación la sustentamos, a nivel preliminar, en el poco trabajo de especialización que hay sobre Monsiváis en el CAC, en las menciones relativamente aisladas de su obra en portales españoles de comunicación, y en el cuerpo relativamente definido y estable de citación en planes y programas. Nos parece que se prueba esa doble dinámica que va de la visibilidad al desconocimiento, lo cual remite a características de ese saber en la comunicación académica mexicana, ya no en la desarticulación institucional o dispersión, sino en la conformación débil de referentes e iconos y saberes.

Suponemos que Monsiváis ha sido objeto de una especie de re-introducción en los estudios de comunicación, claramente con el protagonismo que los estudios culturales tendrían en las escuelas latinoamericanas a partir de los ochenta. Serán autores como Martín-Barbero, Rosana Reguillo o José Manuel

Carlos Monsiváis y el campo académico de la comunicación: • I63 Interacción y sentidos 
Valenzuela, quienes a propósito de mirar a Monsiváis, lo re-insertan por la puerta principalmente de los estudios culturales, lo que supone re-apropiación del autor, que deja de ser principalmente el periodista comprometido o un renovador del lenguaje (como se asoma de la posición que tienen en los planes y programas de estudio), para convertirse en un orfebre del análisis cultural, así aparece como ejemplo en la antología elaborada por el propio Valenzuela (2003) en el que Monsiváis participa en un trabajo sobre la relación entre el público y el cine.

¿Representa Monsiváis ese humanismo "neo-renacentista" disperso, interesado aparentemente en todo y con el principal recurso de una memoria inigualable, además de potencial para leer, ver, escuchar y degustar todo proceso o actividad cultural? En ese sentido, ¿su destino, más que en el pensamiento mismo (porque no aparece referencia alguna en manuales de teorías de comunicación que hayamos revisado ${ }^{7}$ ) es a la iconocidad o simbolismo de una figura, que guarda vínculos con el "intelectual”, el "ciudadano", el habitante de la república de las letras, pero que al mismo tiempo se aleja vía el recurso de un discurso abigarrado de una omnipresencia sui generis, hacia territorios de un debate donde en ocasiones, él parece ser el único convidado.

\section{REFERENCIAS}

Barthes, R. (1987). El susurro del lenguaje. Más allá de la palabra y la escritura. Barcelona: Paidós.

Beristáin, H. (2000). Diccionario de retórica y poética. México: Porrúa.

Castillo, E. \& Tapia, M. (1996). La formación de comunicadores ante los nuevos retos. Ponencia presentada en coloquio "Tradición y Modernidad en la Sociedad Mexicana...”. Universidad de Sonora (México). Disponible en www.cesu.unam. $\mathrm{mx} /$ Ireste/revistas/perfiles/perfiles/75-html/75-07.htm [fecha de consulta, mayo 2003]

Chandler, D. (2001). Semiotics for Beginners. [Libro en línea, noviembre 2004]. Disponible en http://www.aber.ac.uk/media/Documents/S4B/semiotic.html

Fuentes Navarro, R. (2003). La investigación académica sobre comunicación en México. Sistematización documental 1995-2001. México: ITESo.

Fuentes Navarro, R. (1997). "Consolidación y fragmentación de la investigación de la comunicación en México, 1987-1997”. En Comunicación y Sociedad. Universidad de Guadalajara. No. 30.

${ }^{7}$ Estos manuales son los mismos que cita Rizo Marta (2006) "Monográfico. Manuales de teorías de la comunicación: análisis desde la Comunicología”. Barcelona. Portal del INCOM. Artículo en línea. Disponible en http://www.portalcomunicacion.com/

I64 - Tanius Karam Cárdenas 
Fuentes Navarro, R. (1995). La investigación de la comunicación en México. Sistematización documental 1986-1994, México, U de G / ITESo

Fuentes Navarro, R. (1994). "La institucionalización académica de las ciencias de la comunicación: campos, disciplinas, profesiones”. En J. Galindo y C. Luna (coords.). Campo académico de la comunicación: hacia una reconstrucción reflexiva. México: ITESO - CNCA.

Fuentes Navarro, R. (1988). La investigación de Comunicación en México. Sistematización documental 1956-1986. México: EdiCom.

Domínguez, C. (1998). “Carlos Monsiváis, el patricio laico”. En Servidumbre y grandeza de la vida literaria, Joaquín Mortiz, México.

Egan, L. (1992). "Entrevista con Carlos Monsiváis” La Jornada semanal, 26 de enero.

Egan, L. (2001). Carlos Monsiváis: culture and chronicle in contemporary México, Tucson, University of Arizona Press. [Traducción Carlos Monsiváis. Cultura y Crónica en el México contemporáneo, 2004, FCE. México].

Foucault, M. (1999). El orden del discurso. Barcelona: Fábula Tusquetts Editores.

Galindo, J. et al. (2005). Cien libros. Hacia una comunicología posible. México: UACM.

Gómez, H. (2003). "Giros en el pensamiento comunicacional. Para observar las observaciones en la configuración del campo académico de la comunicación en México”. En B. Russi (ed.). X Anuario de la Investigación de la Comunicación CONEICC. México: CONEICC. pp. 235-282.

Karam, T. (2003). "Formas de la entrevista periodística en la reconstrucción de Carlos Monsiváis como figura pública”. En B. Russi (ed.). X Anuario de la Investigación de la Comunicación CONEICC. pp. 73-104.

Karam, T. (2004). "Nota sobre la ironía en la obra de Carlos Monsiváis". En Global Media Journal en Español No 1. Primavera CinCo-ITESM-Monterrey, México. Disponible en http:/gmje.mty.itesm.mx/tanius.html

Karam, T. (2005a). "Algunos funcionamientos discursivos en la obra de Carlos Monsiváis”. En Especulo. Universidad Complutense de Madrid (España). En línea, disponible en http://www.ucm.es/info/especulo/numero30/monsivai.html

Karam, T. (2005b). "Un ejercicio de lectura comparada en la obra periodística de Jorge Ibarguengoitia y Carlos Monsiváis”. En N. A. Cuevas, I. Rodríguez y E. Sánchez (comp.) Homenaje y Diálogo. Primer Coloquio Nacional de Literatura Jorge Ibarguengoitia. México. Universidad de GTO. Facultad de filosofía y Letras. pp. 123-146.

Karam, T. (2006). "A tres caídas sin límite de tiempo. Una introducción a la obra de Carlos Monsiváis". En A. Hernández (coord.). Caleidoscopio crítico de la literatura mexicana contemporánea. México. ITESM-CEM-Miguel Ángel Porrúa. pp. 347-368.

Ruiz, M. (2003). El título y la experiencia: el valor social del licenciado en comunicación. México: UAM-Xochimilco (Cuadernos Tiсом, 48).

Carlos Monsiváis y el campo académico de la comunicación: • I65 Interacción y sentidos 
Salazar, G. J. (2002). "Carlos Monsiváis: de crítico heterodoxo a institución cultural”. En Metapolitica 24-25, Julio-Octubre, 74-84.

Valenzuela, J. M. (2003). Los estudios culturales en México. México: FCE.

Uriarte, E. (1996) "Los intelectuales y los medios de comunicación de masas". En ZER Revista de Estudios en Comunicación No 16. Mayo. País Vasco. España. Artículo en línea. Disponible en http://www.ehu.es/zer/zer1/9notinvuria.htm (fecha de consulta, noviembre 2004). 